\title{
ESI-LC/MS Method Development and Validation for the Determination of Some Selected Antibiotics in Hospital Wastewater
}

Elhag $\mathrm{DE}^{1^{*}}$, Abdallah BS ${ }^{1}$, Hassan $\mathbf{M}^{2,3}$ and Suliman $\mathbf{A}^{1}$

${ }^{1}$ Analytical Research Centre, UMST University, Khartoum, Sudan

${ }^{2}$ Swiss Tropical \& Public Health Institute, Socinstrasse 57, 4051 Basel, Switzerland

${ }^{3}$ Basel University, Peterplatz 1, 4001, Basel, Switzerland

\begin{abstract}
For the last decade, significant attention has been paid to the occurrence, bioaccumaltion and fate of drugs in effluent hospital water. Therefore, the aim of this study was to develop and validate analytical method to identify and quantify the antibiotics tetracycline $\mathrm{HCl}$, (Tetra) doxycycline, (Doxy), ampicillin trihydrate (Ampi), amoxicillin trihydrate (Amoxi) and cephalexin monohydrate (Cefalex). The LCMS instrument used was equipped with with $\mathrm{C} 18$ column, (150 mm length $\times 4.6 \mathrm{~mm}$ inner diameter $x^{5}$ um particle size). The mobile phase was acetonitrile/formic acid (1\%) under gradient elution mode. The MS employs ESI unit and quadrupole mass analyzer. The analysis time was less than 15 minutes. The method was validated in terms of linearity, precision, accuracy, robustness, limit of detection and limit of quantitation, specificity, stability and excellent results were obtained.
\end{abstract}

Keywords: Development; Optimization; LCMS; Antibiotics; Aquatic environment

\section{Introduction}

Antibiotics are natural, semisynthetic or synthetic drugs used as antibacterial, antifungal or antiparasitic. Antibiotics can be grouped by either their chemical structure or mechanism of action [1-3]. Antibiotics represent a major source of micro pollutants as they may as chemical mixtures that exhibit a wide range of mechanisms of action [4-9,1]. Moreover, they can undergo chemical and/or physical reactions leading different metabolites by the action of microorganisms, as well as by other physical or chemical means, resulting in mixtures with higher toxicities and risks to human health than those of the individual compounds $[4,1,10-16]$. In contrast to their therapeutic outcome, these antibiotics often disadvantageous for those target and non-target organisms. In addition to this, improperly disposal of unused antibiotics and nonmetabolized antibiotics excreted by humans can all enter the sewer system in low concentrations. However, the use of antibiotics is growing and their input to the aquatic environment is increasing making them of increasing environmental relevance. The increased awareness that synthetic drugs can lead to serious side effects in the environment has prompted researchers to launch several monitoring studies into the most commonly administered compounds in urban wastewater [1724]. In this work, we developed and validated ESI. LC-MS method for the determination of some antibiotics in hospital waste water.

\section{Materials and Methods}

\section{Antibiotics Standards}

Antibiotics reference standards tetracycline $\mathrm{HCl}$, (Tetra) doxycycline, (Doxy), ampicillin trihydrate (Ampi), amoxicillin trihydrate (Amoxi) and cephalexin monohydrate (Cefalex) were kindly donated by Azal Pharmaceutical, Company, Khartoum Sudan.

\section{Chemicals and reagents}

Acetonitrile, formic acid (HPLC grade), methanol 99\% (analytical grade and HPLC grade), phosphoric acid (98\%), acetone 99\% triethylamine (analytical reagent grade) were purchased from Scharlu, Spain.

\section{Samples}

Three samples were collected from wastewater (sewerage system) and from different locations in Khartoum North Hospital. The samples were preserved and stored in $500 \mathrm{ml}$ amber borosilicate glass bottles to prevent photo degradation. The samples collected were mixed before cleanup.

\section{Samples pretreatment and clean up}

The samples were filtered through 0.45 um filter paper, acidified to $\mathrm{pH} 3.0$ by adding phosphoric $(0.1 \mathrm{M})$ and then were passed through activated C18 cartridge which was activated with $5 \mathrm{ml}$ methanol/water 50:50 (v/v). The cartridge was washed further with $5 \mathrm{ml}$ of acidified water ( $\mathrm{pH}$ 3.) and then was eluted with $5 \mathrm{ml}$ of triethylamine $(5 \%$ $\mathrm{v} / \mathrm{v}$ ) in methanol. The eluted solution was evaporated at normal room temperature $\left(28^{\circ} \mathrm{C}\right)$. Finally, sample was made to $1 \mathrm{ml}$ by adding water/ acetonitrile 95:5 (v/v) and introduced to the LC-MS instrument where $10 \mathrm{uL}$ were injected.

\section{Instrument}

LC-MS 2020 (Shimadzu Corporation, Kyoto, Japan) equipped with C18 column, (150 mm length $\mathrm{x} 4.6 \mathrm{~mm}$ inner diameter $\mathrm{x}^{5}$ um particle size). Pump mode binary gradient (LC-20AD), flow rate $0.5000 \mathrm{ml} / \mathrm{min}$ (Tables 1 and 2).

The LCMS experimental parameters are shown in Table 3.

\section{Preparation of standard solution stock}

A weight of exactly $0.05 \mathrm{~g}$ of each antibiotic tetracycline $\mathrm{HCl}$, (Tetra) doxycycline, (Doxy), ampicillin trihydrate (Ampi), amoxicillin trihydrate (Amoxi) and cephalexin monohydrate (Cefalex) was transferred into a $50 \mathrm{ml}$ volumetric flask and the volume was completed

*Corresponding author: Dhia Eldin Elhag, Analytical Research Centre, UMST University, Khartoum, Sudan, Tel: +249 183 228614; E-mail: magied20@gmail.com

Received January 16, 2018; Accepted January 25, 2018; Published January 31, 2018

Citation: Elhag DE, Abdallah BS, Hassan M, Suliman A (2018) ESI-LC/MS Method Development and Validation for the Determination of Some Selected Antibiotics in Hospital Wastewater. Pharm Anal Acta 9: 578. doi: 10.4172/2153-2435.1000578

Copyright: @ 2018 Elhag DE, et al. This is an open-access article distributed under the terms of the Creative Commons Attribution License, which permits unrestricted use, distribution, and reproduction in any medium, provided the original author and source are credited. 
Citation: Elhag DE, Abdallah BS, Hassan M, Suliman A (2018) ESI-LC/MS Method Development and Validation for the Determination of Some Selected Antibiotics in Hospital Wastewater. Pharm Anal Acta 9: 578. doi: 10.4172/2153-2435.1000578

Page 2 of 6

by the diluents which is acetonitrile and formic acid (1\%), (1:1 v/v) and then ultrasonicated. $1 \mathrm{ml}$ of this solution was transferred into a $10 \mathrm{ml}$ flask and was completed to volume by using the same diluent. From this solution, $1 \mathrm{ml}$ was pipettted into a $10 \mathrm{ml}$ flask and was completed to volume by addition of the same diluent as above to obtain a solution of a concentration of $1 \mathrm{ppm}$.

\begin{tabular}{|c|c|c|c|c|}
$\begin{array}{c}\text { Time } \\
\text { In min }\end{array}$ & Module & command & $\begin{array}{c}\text { Component A value } \\
\text { (formic acid1\%) } \\
\text { Pump A }\end{array}$ & $\begin{array}{c}\text { Component A value } \\
\text { (acetonitrile) } \\
\text { Pump B }\end{array}$ \\
\hline 0.01 & pump & Pump B conc. & 0.00 & 100 \\
\hline 20.00 & pump & Pump B conc. & 70.00 & 30 \\
\hline 22.00 & pump & Pump B conc. & 0 & 100 \\
\hline 25.00 & pump & Pump B conc. & 0 & 100 \\
\hline 25.10 & pump & stop & 0 & \\
\hline
\end{tabular}

Table 1: Gradient elution programme.

\begin{tabular}{|c|c|}
\hline Auto sampler model & SIL-20AC \\
\hline Enable auto sampler & Use \\
\hline Sample rack & Rack $1.5 \mathrm{ml} 105$ vials \\
\hline Rinsing volume & $500 \mathrm{ul}$ \\
\hline Needle stroke & $52 \mathrm{~mm}$ \\
\hline Control vial needle stroke & $52 \mathrm{~mm}$ \\
\hline Rinsing speed & $35 \mathrm{ul} / \mathrm{sec}$ \\
\hline Sampling speed & $15 \mathrm{ul} / \mathrm{sec}$ \\
\hline Purge time & $25.0 \mathrm{~min}$ \\
\hline Rinse mode & Before $/ \mathrm{After}$ \\
\hline Rinse Dip time & $0 \mathrm{sec}$ \\
\hline
\end{tabular}

Table 2: Auto sampler settings.

\begin{tabular}{|c|c|}
\hline Start time & $0.00 \mathrm{~min}$ \\
\hline End time & $25.10 \mathrm{~min}$ \\
\hline Acquisition mode & Scan \& SIM \\
\hline Polarity & Positive \\
\hline Event time & $1.00 \mathrm{sec}$ \\
\hline Detector voltage & $+1.20 \mathrm{kV}$ \\
\hline Start $\mathrm{m} / \mathrm{z}$ & 100.00 \\
\hline End $\mathrm{m} / \mathrm{z}$ & 1000.00 \\
\hline Scan speed & $938 \mathrm{u} / \mathrm{sec}$ \\
\hline Interface & $\mathrm{ESI}$ \\
\hline DL temperature & $250^{\circ} \mathrm{C}$ \\
\hline Nebulizing gas flow & $1.5 \mathrm{~L} / \mathrm{min}$ \\
\hline
\end{tabular}

Table 3: Common MS settings.

\section{Results and Discussion}

During the last two decades LCMS has been extensively used in the environmental research for identification and quantification of pollutants and this due to its performance characteristics such as accuracy reproducibility, low detection limit and sensitivity. The current study reports a novel and validated method for quantitative analysis of nine antibiotics commonly found in hospital effluents using LC-MS. Sample preparation and clean up was achieved by using solidphase technique as it is a powerful sample clean up method in various antibiotic matrices [25-27].

\section{LC-MS soptimization}

Several gradient programs were tried to achieve the optimum separation of the entire antibiotics standard. Gradient elution was necessary to avoid excessive retention. Well resolved peaks were obtained within short analysis time.

The positive and the negative electrospray ionization (ESI) scan modes were investigated for attaining the highest sensitivity during the method development process. The full scan of the antibiotics mixture in positive mode showed that the signal-to- noise ratios obtained in this mode were higher than those of the in negative mode. Hence, positive mode was used to obtain the precursor ion $[\mathrm{M}+\mathrm{H}]$ for the qualitative and quantitative analysis $[9,17,28-31]$. During the method development, the quadrupole mass analyzers operated in selected ion monitoring (SIM) mode where it monitors only a few mass-tocharge ratios. By using electrospray ionization and subsequent analysis produced the chromatogram shown in Figure 1.

Although all peaks were well resolved in this study, LC MS capability allows analysis of co-eluted analytes. This allows fast analysis time and minimal sample preparation. Table 4 shows the precursor ion and the retention time.

\section{Method performances and validation}

Developing and validation of a method for LC-MS involves demonstrating all the performance characteristics such as linearity, precision, accuracy, limits of detection and quantitation, solution stability and robustness [32]. The linearity of a test procedure is its ability (within a given range) to produce results that are directly proportional to the concentration of analyte in the sample. Acceptability of linearity data is often judged by examining the correlation coefficient $\left(\mathrm{r}^{2}\right)$ and $y$-intercept of the linear regression line for the response versus concentration plot. Regression line equations are shown in Table 5. Excellent correlation between the instrumental response and the concentration were obtained.

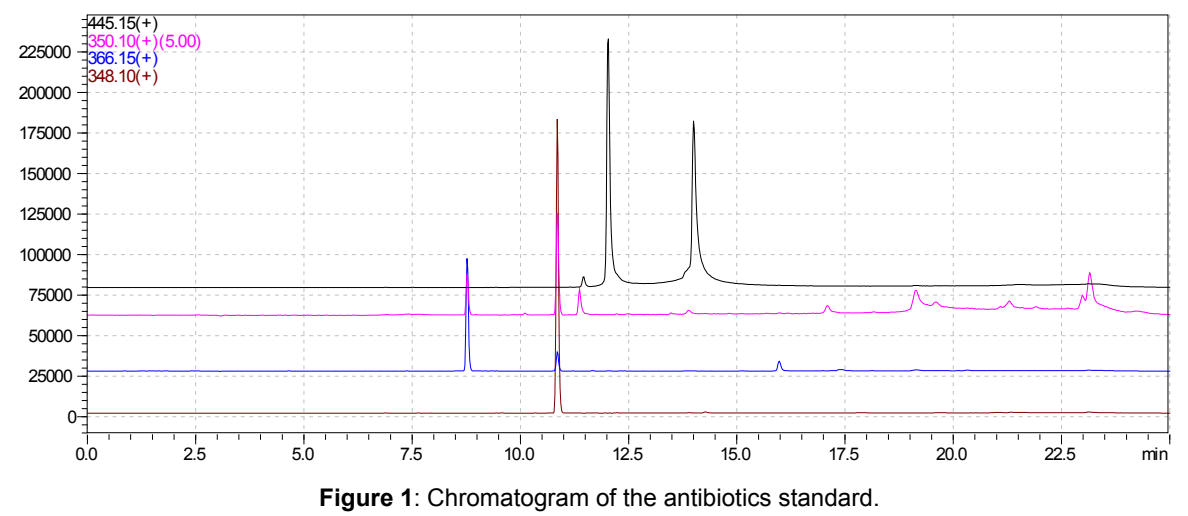


Citation: Elhag DE, Abdallah BS, Hassan M, Suliman A (2018) ESI-LC/MS Method Development and Validation for the Determination of Some Selected Antibiotics in Hospital Wastewater. Pharm Anal Acta 9: 578. doi: 10.4172/2153-2435.1000578

Page 3 of 6

\begin{tabular}{|c|c|c|}
\hline Drug & Retention time & M/z \\
\hline Tetra & 12.034 & 445.15 \\
\hline Doxy & 14.014 & 445.15 \\
\hline Ampi & 10.862 & 350.1 \\
\hline Amoxi & 8.773 & 366.15 \\
\hline Cefalex & 10.858 & 348.1 \\
\hline
\end{tabular}

Table 4: The ion peaks $(\mathrm{M} / \mathrm{z})$ and the retention times of the antibiotic standards.

\begin{tabular}{|c|c|c|}
\hline Drug & Regression line equation & $\mathbf{R}^{\mathbf{2}}$ \\
\hline tetra & $\mathrm{Y}=86865 \mathrm{x}-14669$ & 0.999 \\
\hline Doxy & $\mathrm{Y}=1 \mathrm{E} 06 \mathrm{x}+11923$ & 0.999 \\
\hline Ampi & $\mathrm{Y}=37168 \mathrm{x}-2454$ & 0.998 \\
\hline Amoxi & $\mathrm{Y}=41663 \mathrm{x}-1983$ & 0.998 \\
\hline Cefalex & $51884 \mathrm{x}+22985$ & 0.999 \\
\hline
\end{tabular}

Table 5: The linearity testing results.

\begin{tabular}{|c|c|c|c|c|c|c|c|c|c|}
\hline Drug & 1 & 2 & 3 & 4 & 5 & 6 & AVG & SD & RSD \\
\hline tetra & 1756479 & 1759324 & 1781687 & 1759548 & 1793867 & 1753518 & 1767404 & 16391.91 & 0.93 \\
\hline Doxy & 1685461 & 1650101 & 1679713 & 1621835 & 1652958 & 1639810 & 1654980 & 24072.5 & 1.45 \\
\hline Ampi & 102656 & 103065 & 103160 & 103330 & 104035 & 103103 & 103224.8 & 455.1032 & 0.44 \\
\hline Amoxi & 552041 & 551651 & 554843 & 561591 & 556520 & 571101 & 557957.8 & 7382.376 & 1.32 \\
\hline Cefalex & 1429264 & 1428162 & 1431949 & 1434767 & 1442267 & 1425304 & 1431952 & 6001.813 & 0.42 \\
\hline
\end{tabular}

Table 6: The results of repeatability testing.

\begin{tabular}{|c|c|c|c|c|c|}
\hline \multicolumn{7}{|c|}{ Day 1 } & \multicolumn{2}{|c|}{ Day 2 } \\
\hline Drug & SD & RSD & SD & RSD \\
\hline tetra & 34824.82 & 1.93428 & 20111.91 & 1.083573 & 14413.97 \\
\hline Doxy & 33701.61 & 1.917657 & 32774.64 & 1.942115 & 0.78 \\
\hline Ampi & 1556.515 & 1.542105 & 918.1362 & 0.81053 & 15980.39 \\
\hline Amoxi & 3936.037 & 0.642846 & 10674.47 & 1.702397 & 0.95 \\
\hline Cefalex & 10462.19 & 0.702811 & 15534.94 & 0.994861 & 1.5576 \\
\hline
\end{tabular}

Table 7: The results of reproducibility testing.

\begin{tabular}{|c|c|c|c|}
\hline & & $\mathbf{8 0}$ & $\mathbf{1 0 0 \%}$ \\
\hline tetra & std con & 101.9607 & 99.99998 \\
\hline Doxy & 1 & 101.6675 & 100 \\
\hline Ampi & 1 & 99.5806 & 101.8249 \\
\hline Amoxi & 1 & 99.17957 & 99.87969 \\
\hline Cefalex & 1 & 100.0237 & 99.71749 \\
\hline
\end{tabular}

Table 8: The accuracy test results.

\begin{tabular}{|c|c|c|}
\hline Drug & LOD & LOQ \\
\hline tetra & 0.02 & 0.12 \\
\hline Doxy & 0.02 & 0.18 \\
\hline Ampi & 0.02 & 0.22 \\
\hline Amoxi & 0.08 & 0.8 \\
\hline Cefalex & 0.02 & 0.05 \\
\hline
\end{tabular}

Table 9: The results of Limit of detection and quantitation testing.

The precision of the method (intraday) was examined by repeatedly injecting the antibiotic solutions. Precision criteria for an assay method are that the instrument precision and the intra-assay precision (RSD) will be $\leq 2 \% .0 .28 \%$ RSD. The intraday precision was in the range of $1.450-44 \%$ (Table 6).

Excellent values were obtained for interday precision and the values range was 0.78-1.39 (Table 7).

The accuracy of the method was evaluated by determination of the recovery of the antibiotics at four concentration levels (80,100 and 130\%). The accuracy of the method was determined by calculating recoveries of each standard. The results showed good recoveries (Table 8).

The limit of detection (LOD) and the limit of quantitation (LOQ) and for the analyzed samples were calculated using the standard deviation of the response $(\sigma)$ and the slopes (s) i.e. $\mathrm{LOD}=3.3 \sigma / \mathrm{s}$ and $\mathrm{LOQ}=10 \mathrm{\sigma} / \mathrm{s}$. Low detection and quantitation limits were obtained (Table 9). 
Citation: Elhag DE, Abdallah BS, Hassan M, Suliman A (2018) ESI-LC/MS Method Development and Validation for the Determination of Some Selected Antibiotics in Hospital Wastewater. Pharm Anal Acta 9: 578. doi: 10.4172/2153-2435.1000578

Page 4 of 6

\begin{tabular}{|c|c|c|c|c|c|c|c|}
\hline Drug & injection1 & injection2 & AVG area & std area & std con & found con & AVG RE \% \\
\hline tetra & 1813011 & 1856073 & 1834542 & 1856073 & 1 & 0.9884 \\
\hline Doxy & 1788795 & 1687575 & 1738185 & 1687575 & 1.02999 & 102.999 \\
\hline Ampi & 108434 & 113276 & 110855 & 113276 & 1 & 0.978627 \\
\hline Amoxi & 572373 & 627026 & 599699.5 & 627026 & 0.956419 & 95.64189 \\
\hline Cefalex & 1502397 & 1561519 & 1531958 & 1561519 & 1 & 1 \\
\hline
\end{tabular}

Table 10: The solution stability test results.
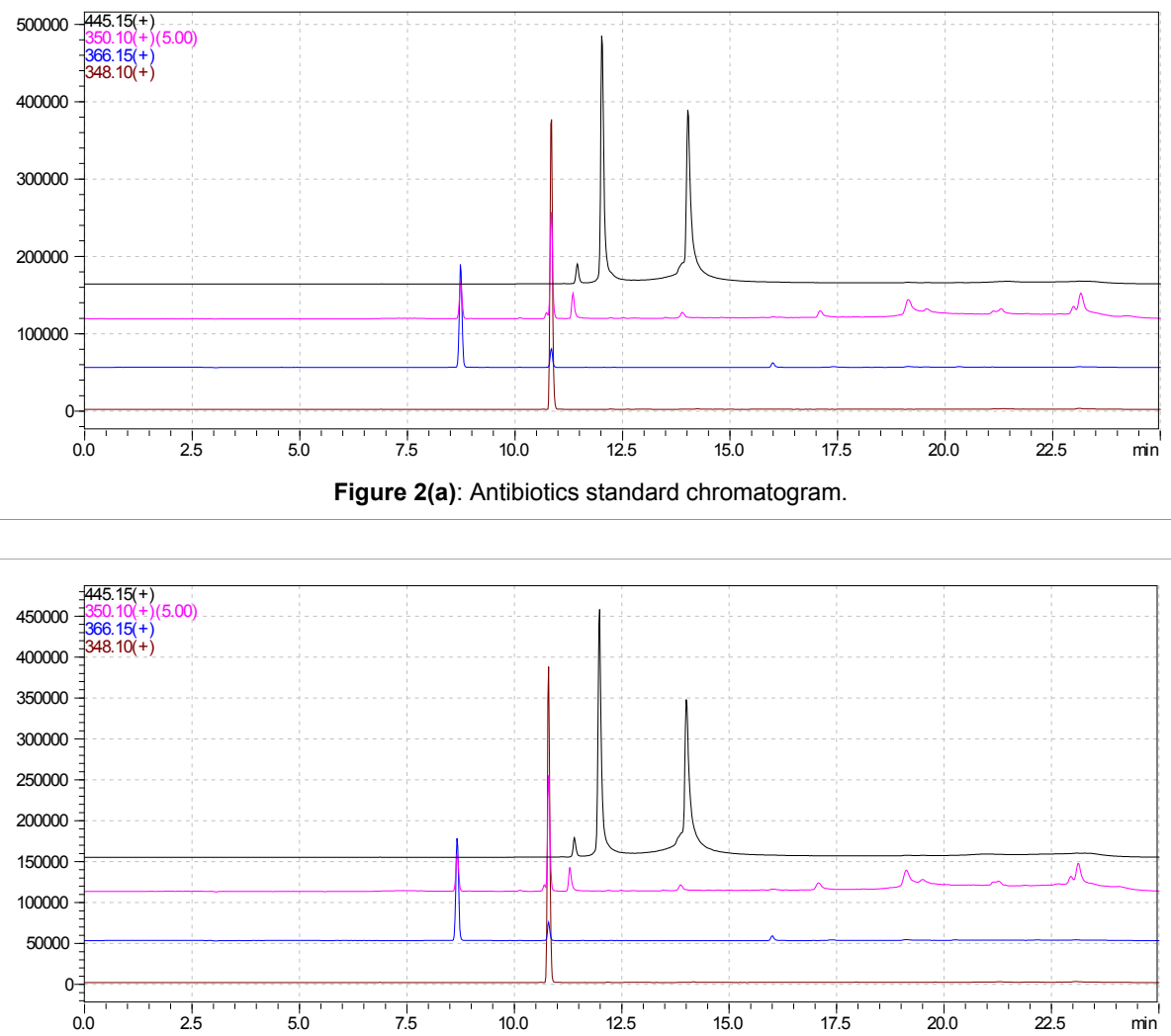

Figure 2(b): Antibiotics standard chromatogram after six hours from the first injection.

Specificity which is the ability of the method to accurately measure the analyte response in the presence of all potential sample components. The obtained results blank injection showed absence of any interferents. Solution stability of the antibiotics standards solution was also assessed after $6 \mathrm{~h}$ room temperature storage. For solutions to be considered stable, the results of the percentage difference between the mean response for the fresh and stored solutions should be $\leq 5.0 \%$ (Figure 2a, 2b and Table 10).

Robustness which is the reliability of an analysis with respect to deliberate variations in method parameters of an analytical procedure should show the reliability of an analysis with respect to deliberate variations in method parameters. The evaluation of robustness should be considered during the development phase. The standard $\mathrm{pH}$ was 3.0 and the room temperature was $28^{\circ} \mathrm{C}$. These two parameters were varied in order to evaluate the robustness of the methods and excellent results are shown in Table 11.

\section{Sample Analysis}

The developed method was applied for the determination of antibiotics in hospital wastewater samples. The results of the sample analyses are tetracycline $\mathrm{HCl}$, doxycycline, and cephalexin monohydrate with concentrations of $0.124,0.134$ and $0.084 \mathrm{ppm}$, respectively. Ampicillin trihydrate and amoxicillin trihydrate were not detected (Figure 3).

Such findings necessitate the need for more efficient wastewater treatment plants and stricter quality control measures. However, there numerous routes by which the disposed of antibiotics and other drugs can reach aquatic environment. However, antibiotics persist and degrade slowly, pass through water treatment plants and thereafter transported to sediment or aquatic environment.

Chemical degradation includes hydrolysis oxidation, decarboxylation, isomerization and elimination. Hydrolysis spitting by water, is a potential degradation pathway for organic pollutants in the aquatic environment and it is probably the most commonly encountered mode of drug degradation. Examples of antibiotics that undergo hydrolysis include lactones, amide sand macrolides. The $\mathrm{pH}$ has a profound effect in hydrolysis reaction. For instance, at neutral $\mathrm{pH}$, hydrolysis of sulphonamides is very slow whereas lactams hydrolyse under acidic conditions [33-37]. It is noteworthy that the environmental occurrence, persistence, fate and bioaccumulation ability of antibiotics differ depending on their chemical properties and on the environmental conditions $[38,39]$. 
Citation: Elhag DE, Abdallah BS, Hassan M, Suliman A (2018) ESI-LC/MS Method Development and Validation for the Determination of Some Selected Antibiotics in Hospital Wastewater. Pharm Anal Acta 9: 578. doi: 10.4172/2153-2435.1000578

Page 5 of 6

\begin{tabular}{|c|c|c|c|c|c|c|c|}
\hline Parameter & Drug & Run1 & Run2 & Run3 & AVG & SD & RSD \\
\hline \multirow[t]{5}{*}{$29^{\circ} \mathrm{C}$} & tetra & 1761821 & 1759775 & 1768001 & 1763199 & 4282.631 & 0.24289 \\
\hline & Doxy & 1560235 & 1558049 & 1532373 & 1550219 & 15493.69 & 0.999452 \\
\hline & Ampi & 99096 & 99071 & 101316 & 99827.67 & 1288.995 & 1.29122 \\
\hline & Amoxi & 548559 & 537823 & 546558 & 544313.3 & 5709.144 & 1.048871 \\
\hline & Cefalex & 1382887 & 1401628 & 1399124 & 1394546 & 10174.6 & 0.729599 \\
\hline \multirow[t]{5}{*}{$27^{\circ} \mathrm{C}$} & tetra & 1787640 & 1768801 & 1789080 & 1781840 & 11315.32 & 0.635036 \\
\hline & Doxy & 1677628 & 1649295 & 1647241 & 1658055 & 16982.09 & 1.024218 \\
\hline & Ampi & 98033 & 98845 & 98586 & 98488 & 414.7758 & 0.421144 \\
\hline & Amoxi & 541732 & 546526 & 546459 & 544905.7 & 2748.68 & 0.504432 \\
\hline & Cefalex & 1371988 & 1383966 & 1367474 & 1374476 & 8522.859 & 0.620081 \\
\hline \multirow[t]{5}{*}{ PH3.1 } & tetra & 1713358 & 1704663 & 1714488 & 1710836 & 5376.036 & 0.314234 \\
\hline & Doxy & 1571982 & 1554607 & 1544523 & 1557037 & 13889.89 & 0.892072 \\
\hline & Ampi & 92592 & 92732 & 94447 & 93257 & 1032.945 & 1.107632 \\
\hline & Amoxi & 491749 & 497037 & 503680 & 497488.7 & 5978.31 & 1.201698 \\
\hline & Cefalex & 1296192 & 1316877 & 1319020 & 1310696 & 12606.74 & 0.961835 \\
\hline \multirow[t]{5}{*}{$\mathrm{PH} 2.9$} & tetra & 1601163 & 1615916 & 1621137 & 1612739 & 10359.14 & 0.642332 \\
\hline & Doxy & 1576493 & 1554135 & 1556553 & 1562394 & 12270.09 & 0.785339 \\
\hline & Ampi & 95074 & 94744 & 95123 & 94980.33 & 206.1318 & 0.217026 \\
\hline & Amoxi & 501861 & 511828 & 513200 & 508963 & 6188.651 & 1.215933 \\
\hline & Cefalex & 1312012 & 1326165 & 1341340 & 1326506 & 14666.97 & 1.105684 \\
\hline
\end{tabular}

Table 11: The results of robustness testing.

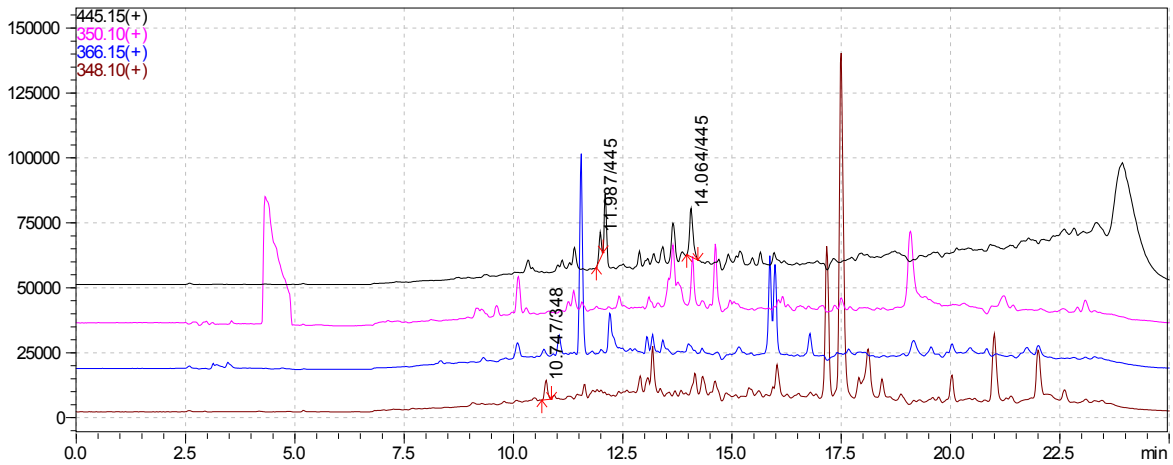

Figure 3: chromatograms of the antibiotic found in hospital effluent sample.

\section{Conclusion}

A novel LC-MS method was developed for analysis of amoxicillin trihydrate, ampicillin trihydrate, cephalexin monohydrate, norfloxacin $\mathrm{HCl}$, ciprofloxacin, tetracycline $\mathrm{HCl}$, azithromycin, doxycycline and clarythromycin. The method proved to be accurate, precise linear, reproducible and robust. The method can be used conveniently for identification and quantification of these antibiotics in aqueous samples.

\section{References}

1. Schneider T, Müller A, Miess H, Gross H (2014) Cyclic lipopeptides as antibacterial agents-potent antibiotic activity mediated by intriguing mode of actions. Int J Med Microbiol 304: 37-43.

2. Hirota-Takahata Y, Kozuma S, Kuraya N, Fukuda D, Nakajima M, et al. (2017) Ogipeptins, novel inhibitors of LPS: physicochemical properties and structural elucidation. J Antibiot 70: 84-89.

3. Kozuma S, Hirota-Takahata Y, Fukuda D, Kuraya N, Nakajima M, et al. (2014) Screening and biological activities of pedopeptins, novel inhibitors of LPS produced by soil bacteria. J Antibiot 67: 237-242.

4. Szekeres E, Baricz A, Chiriac CM, Farkas A, Opris O, et al. (2017) Abundance of antibiotics, antibiotic resistance genes and bacterial community composition in wastewater effluents from different Romanian hospitals. Environ Pollut 225 304-315.

5. Bouki C, Venieri D, Diamadopoulos E (2013) Detection and fate of antibiotic resistant bacteria in wastewater treatment plants: a review. Ecotoxicol Environ Saf 91: 1-9.

6. Jiang Y, Li M, Guo C, An D, Xu J, et al. (2014) Distribution and ecological risk of antibiotics in a typical effluent-receiving river (Wangyang River) in north China. Chemosphere 112: 267-74

7. Ben W, Wang J, Cao R, Yang M, Zhang Y, et al. (2017) Distribution of antibiotic resistance in the effluents of ten municipal wastewater treatment plants in China and the effect of treatment processes. Chemosphere 172: 392-398.

8. Zhang S, Han B, Gu J, Wang C, Wang P, et al. (2015) Fate of antibiotic resistant cultivable heterotrophic bacteria and antibiotic resistance genes in wastewater treatment processes. Chemosphere 135: 138-145

9. García-Galán MJ, Díaz-Cruz MS, Barceló D (2010) Determination of 19 sulfonamides in environmental water samples by automated on-line solidphase extraction-liquid chromatography-tandem mass spectrometry (SPE LC-MS/MS). Talanta 81: 355-366.

10. López-Serna R, Petrović M, Barceló D (2012) Occurrence and distribution of multi-class pharmaceuticals and their active metabolites and transformation products in the Ebro River basin (NE Spain). Sci Total Environ 440: 280-289.

11. Afonso-Olivares C, Sosa-Ferrera Z, Santana-Rodríguez JJ (2017) Occurrence 
Citation: Elhag DE, Abdallah BS, Hassan M, Suliman A (2018) ESI-LC/MS Method Development and Validation for the Determination of Some Selected Antibiotics in Hospital Wastewater. Pharm Anal Acta 9: 578. doi: 10.4172/2153-2435.1000578

and environmental impact of pharmaceutical residues from conventional and natural wastewater treatment plants in Gran Canaria (Spain). Sci Total Environ 599: 934-943.

12. Mohapatra S, Huang $\mathrm{CH}$, Mukherji S, Padhye LP (2016) Occurrence and fate of pharmaceuticals in WWTPs in India and comparison with a similar study in the United States. Chemosphere 159: 526-535

13. Deng W, Li N, Zheng H, Lin $\mathrm{H}$ (2016) Occurrence and risk assessment of antibiotics in river water in Hong Kong. Ecotoxicol Environ Saf 125: 121-127.

14. Zhang R, Zhang G, Zheng Q, Tang J, Chen Y, et al. (2012) Occurrence and risks of antibiotics in the Laizhou Bay, China: impacts of river discharge Ecotoxicol Environ Saf 80: 208-215.

15. Wilkinson J, Hooda PS, Barker J, Barton S, Swinden J (2017) Occurrence, fate and transformation of emerging contaminants in water: An overarching review of the field. Environ Pollut 231:954-970.

16. Rodriguez-Mozaz S, Chamorro S, Marti E, Huerta B, Gros M, et al. (2015) Occurrence of antibiotics and antibiotic resistance genes in hospital and urban wastewaters and their impact on the receiving river. Water Res 69: 234-242.

17. Imran M, Tawab A, Rauf W, Rahman M, Khan QM, et al. (2017) LC-MS/MS based method development for the analysis of florfenicol and its application to estimate relative distribution in various tissues of broiler chicken. J Chromatogr B Analyt Technol Biomed Life Sci 1063: 163-173.

18. Yuan Q-B, Guo M-T, Yang J (2014) Monitoring and assessing the impact of wastewater treatment on release of both antibiotic-resistant bacteria and their typical genes in a Chinese municipal wastewater treatment plant. Environ Sci Process Impacts 16: 1930-1937.

19. Iglesias A, Nebot C, Vázquez BI, Coronel-Olivares C, Abuín CMF, et al. (2014) Monitoring the presence of 13 active compounds in surface water collected from rural areas in northwestern Spain. Int $\mathrm{J}$ Environ Res Public Health 11: $5251-5272$.

20. Frédéric $O$, Yves $P$ (2014) Pharmaceuticals in hospital wastewater: thei ecotoxicity and contribution to the environmental hazard of the effluent. Chemosphere 115: 31-39.

21. Yi X, Bayen S, Kelly BC, Li X, Zhou Z (2015) Improved detection of multiple environmental antibiotics through an optimized sample extraction strategy in liquid chromatography-mass spectrometry analysis. Anal Bioanal Chem 407 9071-9083.

22. Verlicchi P, Al Aukidy M, Galletti A, Petrovic M, Barceló D (2012) Hospital effluent: investigation of the concentrations and distribution of pharmaceuticals and environmental risk assessment. Sci Total Environ 430: 109-118.

23. Teixeira S, Delerue-Matos C, Alves A, Santos L (2008) Fast screening procedure for antibiotics in wastewaters by direct HPLC-DAD analysis. J Sep Sci 31: 2924-2931.

24. Gros M, Rodríguez-Mozaz S, Barceló D (2012) Fast and comprehensive multiresidue analysis of a broad range of human and veterinary pharmaceuticals and some of their metabolites in surface and treated waters by ultra-highperformance liquid chromatography coupled to quadrupole-linear ion trap tandem mass spectrometry. J Chromatogr A 1248: 104-121.
25. Rossmann J, Schubert S, Gurke R, Oertel R, Kirch W (2014) Simultaneous determination of most prescribed antibiotics in multiple urban wastewater by SPE-LC-MS/MS. J Chromatogr B Analyt Technol Biomed Life Sci 969: 162170.

26. Cui $X$, Zhang $P$, Yang $X$, Yang M, Zhou W, et al. (2015) $\beta$-CD/ATP composite materials for use in dispersive solid-phase extraction to measure (fluoro) quinolone antibiotics in honey samples. Anal Chim Acta 878: 131-139.

27. Panditi VR, Batchu SR, Gardinali PR (2013) Online solid-phase extractionliquid chromatography-electrospray-tandem mass spectrometry determination of multiple classes of antibiotics in environmental and treated waters. Ana Bioanal Chem 405: 5953-5964.

28. Niessen WM (1998) Analysis of antibiotics by liquid chromatography-mass spectrometry. J Chromatogr A 812: 53-75.

29. Saussereau E, Lacroix C, Guerbet M, Cellier D, Spiroux J, et al. (2013) Determination of levels of current drugs in hospital and urban wastewater. Bull Environ Contam Toxicol 91: 171-176.

30. Vosough M, Rashvand M, Esfahani HM, Kargosha K, Salemi A (2015) Direct analysis of six antibiotics in wastewater samples using rapid high-performance liquid chromatography coupled with diode array detector: a chemometric study towards green analytical chemistry. Talanta 135: 7-17.

31. Di Corcia A, Nazzari M (2002) Liquid chromatographic-mass spectrometric methods for analyzing antibiotic and antibacterial agents in animal food products. J Chromatogr A 974: 53-89.

32. https://www.fda.gov/

33. Hou JP, Poole JW (1969) Kinetics and mechanism of degradation of ampicillin in solution. J Pharm Sci 58: 447-454.

34. Vasconcelos TG, Henriques DM, König A, Martins AF, Kümmerer K (2009) Photo-degradation of the antimicrobial ciprofloxacin at high $\mathrm{pH}$ : identification and biodegradability assessment of the primary by-products. Chemosphere 76 : 487-493.

35. Volmer DA, Hui JP (1998) Study of erythromycin A decomposition products in aqueous solution by solid-phase microextraction/liquid chromatography/ tandem mass spectrometry. Rapid Commun Mass Spectrom RCM 12: 123129

36. Sturini M, Speltini A, Maraschi F, Pretali L, Ferri EN, et al. (2015) Sunlightinduced degradation of fluoroquinolones in wastewater effluent: photoproducts identification and toxicity. Chemosphere 134: 313-318.

37. Torniainen K, Tammilehto S, Ulvi V (1996) The effect of $\mathrm{pH}$, buffer type and drug concentration on the photodegradation of ciprofloxacin. Int J Pharm 132 53-61.

38. Kümmerer K (2008) Pharmaceuticals in the Environment. Springer, Germany.

39. Ye Z, Weinberg HS, Meyer MT (2007) Trace analysis of trimethoprim and sulfonamide, macrolide, quinolone, and tetracycline antibiotics in chlorinated drinking water using liquid chromatography electrospray tandem mass spectrometry. Anal Chem 79: 1135-1144. 